\title{
Consulta Conjunta: uma Estratégia de Capacitação para a Atenção Integral à Saúde
}

\author{
Joint Consultation: a Training Strategy for \\ Comprehensive Health Care
}

Júlio de Mello Filho

Lia Márcia Cruz da Silveira ${ }^{2}$

PALAVRAS-CHAVE

- Prática de Saúde Pública;

-Aprendizagem;

- Área de.Atuação Profissional.

KEY-WORDS

- Public Health Practice;

-Learning;

- Professional Professional Location.

Recebido em: 21/09/2004

Reencaminhado em: 15/04/2005

Aprovado em: 11/05/2005

147 REVIST BRASIHARA DE EDUCACTO MEDACS

47 Rio de JaAeito, $v .29, x^{*} 2$, maio/aga. 2003
${ }^{7}$ Médico. Professor Títular de Psicologia Médica, Faculdade de Ciências Médicas, Universidade do Estado do Rio de Janeiro. Rio de Janeiro, Brasil.

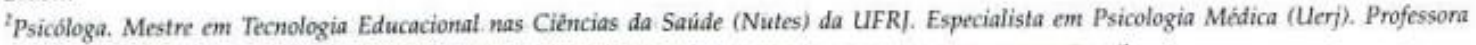
Assistente, Faculdade de Medicina, Universidade do Grande Rio. Duque de Caxias, Rio de Janeiro, Brasil. 


\section{INTRODUÇÃO}

Atualınente, muito se tem discutido, no Brasil, sobre como produzir estratégias na formaçăo que provoquem mudanças objetivas na prática dos profissionais de saúde de forma a prestar uma atenção integral $e$ humanizada às pessoas'. Neste contexto, têm sido alvo de discussões os diferentes cenários de aprendizăgem, modos de inserção na prática, concepçōes pedagógicas, metodologias de ensino, processos avaliativos que contemplem conhecimentos, habilidades e atitudes'; enfim, uma mescla de aspectos da formaçāo que, conjugados, instrumentalizem o profissional para atuar em sintonia com as necessidades e demandas de saúde da população. É nesta perspectiva que apresentamos este artigo, uma prática de ensino $\mathrm{em}$ serviço denominada Consulta Conjunta, originária da Interconsulta, que visa integrar pessons e saberes no cotidiano dos serviços de saúde, objetivando sensibilizar, mobilizar e capacitar para mudar concepçðes, práticas c relações a fim de proporcionar cuidado integral à saúdc.

\section{BREVE HISTÓRICO}

A Interconsulta ' ú uma ação de saúde interprofissional e interdisciplinar que tem por objetivo integrar c promover a troca de saberes de diferentes atores que atuam nos serviços de saúde, visando o aprimoramento da tarefa assistencial. Fazse por meio de pedido de parecer, discussão de caso e consulta conjunta.

$\wedge$ Consulta Conjunta, como o nome indica, reúne, na mesma cena, profissionais de diferentes categorias, o paciente e, se neccssário, a familia deste. $\Lambda$ açāo se faz a partir da solicitação de un dos profissionais para complementar e/ou elucidar aspectos da situação de cuidado $\mathrm{em}$ andamento que fujam ao entendimento do solicitante ao traçar uma conduta terapêutica. Este artigo focará a parceria entre o médico (solicitante) e o profissional psi (psicólogo ou psiquiatra solicitado), junto ao paciente.

$\wedge$ Consulta Conjunta nasceu de forma prática, de acordo com o relato de seu criador, o professor Júlio de Mello Filho:

Em meados de 1997, era ell um prufessor de Psicolugia Médica do entio Hospital Universitirio Clementino Fraga Fillıo da

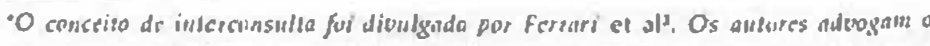

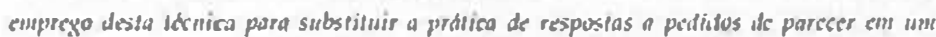
hospilal de Psignindriat - o liuspfeio de las Mercedes em Buenos dires. Segundos us

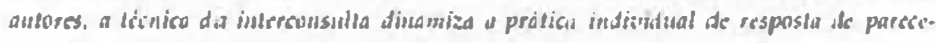

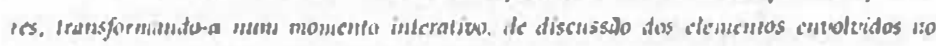

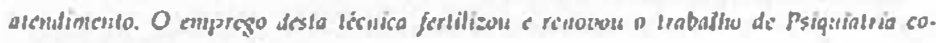
whecido tantrin conso liggasio.
}

Universidade Federal do Rio de lanciro (HUCFF/(UFR/) quando um interno de medicina me procurou pedindo que atendesse uma puciente com um quadro de asma brónquica refratiria ao approach médico que estarn scudo utilizado. Eu centro the propus, como cosinmo fazer nestes casos: 'Podemos ver a paciente jumlos?', ao que ele concordou.

Fizcmos, entño, umn entrevista a três, na qual estabeleci contato com unn paciente branca, soltcira, de meia-idade, ansiosa, com um quadro de asma refratario ao tratamento médico habilunl com broncodilatadores e corlicbides.

O fato de conliecer a doenı̧a be'm, do pouto de vista clinico. foi importante para o interno poder valorizesr men enfoque, segundo deprecendi de sua conduta. Logo percebi que a cxacerbaçĩu du doenşa da paciente e'stava ligada a uma condiçrio de luto nion resolvido pelo fato de sen fillo únicu ler ido morare traba. Ihar muma cidade distaute, com poucas possibilidades de se visitarem. Propus, entro, um enfoque de duas consultas semanais, mum lotal de oito, durante as quais abordamos se'u caso com a presensal do interno. Ele cra interessado e'm questōes psicológicas e concordou $\mathrm{em}$ participar da experiêucia de psicuterapia breve, durante a qual dirigia perguntas e metilo escassas opiniises, pois se tratavu, obviamente, de um novo campo de trabalho para ele. De minha parte, me permiti opinar sobre a medicaçãe da paciente de forma nกิ intrusiva. Tentava, assim, manter a perspectivn de uma conduta realmente conjunta.

A psicolerapia cvoluiu como muitas outras c'm semelhanles cond içues, de um Iuto patologgico - que eu jó chamei de luto corporal - para um luto mais normal, prescindiudo das reaçós de estresse que mantiuluam o processo de somatizaçio funcionando, sendo o pulmào o úrgio de expressiono de todo o sofrimento vivido pela paciente, porém nio conscientizado. As ctapas do luto - poder se queixar do objeto, poder accitar a distância destc, poder perdoar o objeło - foram vividas, c, entảo, as meetas da terapia breve foram cumpridas. Pòde-se traba. lliar a alta da paciente, que ficou sendo alendida pelo interno quinzenalmente por se tratar de uma condiçno crônica ce sujeita a agravamentos.

Duranle loda a experiência lerapêutica vivida conjuntamente, en esclarecia detalhes da psicodinâmica da paciente, da licrica que estiva se'ndo empregada, e o interno me informava de sua evoluçūo clinico-medicamentosa. Após a alta da paciente. cle passou a frequicutar o Grupo Balint" que cu mantinta naquele hospital, de modo interessado. Eventualmente, ete me informava sobre o estado da paciente, que evolzin bem durante o

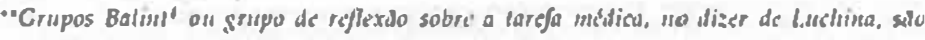

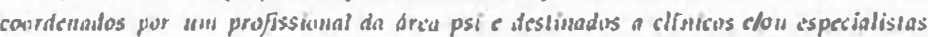

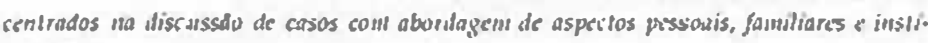
incionals.
} 


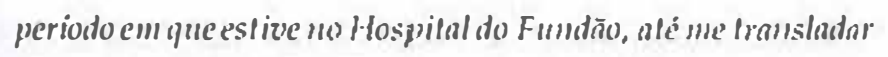
para o hospital Pedro Ermesto, onde esfon afe lwoje.

No HUCFF/UFR], de'se'nvolvemos esia e'xperiêncin com outros casos ce contão a repuelinos no Hosputal Universitirio Pedro Ernesto, da Universidade Estadual do Rio the Janeiro (Mupel Uerj), inicialmente com alumos do tereceiro andu do curso meifico. Conn estes, ane inicinum seus primeiros confafos com pucien. tes, purticiprivumos da lcilura da ananmese' de modo conjunlo,

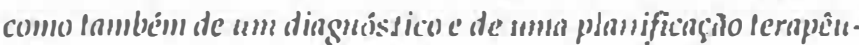

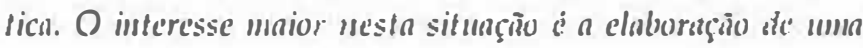
anummese auc integra aspectos subjefivos e objefizos que chvolvem o advecer, já que o aluno desta sírie aimda está punci) amadurecido acadennicamcinte: para parficipur dess outros itens de uma obserzagiono clinica.

Percebemos, 110 präfica, que uma importante área de aplicaçno da Consulta Conjunta é o trabulhu umbulatorial nas unidades clinicas onde a Psicologia Médica esfiver representada. Ali estão presentes, basicanente, iulernos e residentes que realizam seu trabalho de dingrusisticue tratamenfo de pessuas em alendimento. Mesino que já ténham tomado conlalo com conceilos de Psicologia Médica, eles se sénfem insegeress diante dos problemas psicológicus apresentados pelos pacientes, prese'nles em cerca de $70 \%$ dos casos, segundo virins esfatisficas afuais.

Entro nos pergumtam: 'Quer ver este caso para mim?'. Ao que respondemos: 'Podemos ver jumlos?'. E, deste modo, sem

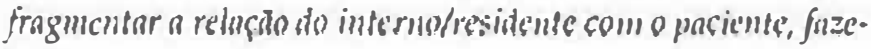
mos umma aboridagem comjugada, sempre com o cuidado de qui nossas opinizes's tenham valéncias livre's para que o donforanido possn interagir conosco.

Deste modo, cimmprimos, de forma prática, as ctapns de umma amammese psicossommálica ed de unn diugnóstico psicológico (ou psiguiálrico, se for o caso) sempre a qualro mãos. Se mäo houver tempo on condiçoes para umn condula mais integral, respondemos auestues formuladas pelus colegas, sempre cuidando para que se questione'm fambim.

Quanto ao se'guiménfo psicoteráprico a dois, mem semupre $\dot{e}$ possivel, por pouca disponilvilidade de lempo peros infernos/ residentes ou por desinteresse por un enforgue psicoligico mais

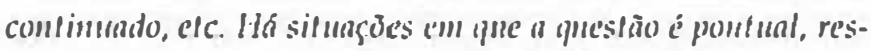
Irita a umn ou duas consullas para " clarificaçño de uma conduta mais atequadu.

Um dos pontos essencinis da Consulla Comjuntu é umu cadtu um dos parficipantes aprenda com o oulro sobre as técnicas de abordagem ulilizadus, reconlhecendo as recursos lera-

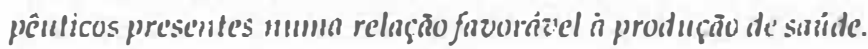
Deste modo, o clinico aprenderi com o profissional psi e este aprenderi mais sobre aspecles clinicos das enfermidades em questio.

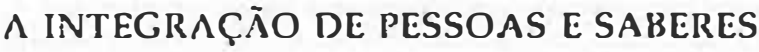

\Consulta Conjunta é uma ação de saúde que tem como caracteristica unir o viés assistencial ao pedagúgico na medida cm que integra pessoas e saberes na aprendizagem em servi५o. Tem por objetivo aprimorar a tarefa assistencial no que diz respeito à qualidade da assistência e à qualificação prof̈issional e surge da necessidade viva de dar respostas resolutivas durante a dinâmica ágil da assistência đà saúde. Atualmentc, a Consulta Conjunta vem sendo exercitada nos Ambulatórios do ILospital Universitärio Pedro Ermesto da Universidade do Estado do Rio de Janciro (HUPE/UERJ), com o propósito de capacitar médicos e psicúlogess para a prática do cuidado integral à saúde. Este recurso de capacitaçōo profissional em serviço tem objetivos comuns e especificos referentes ans diferentes atores envolvidos.

Entre os objetivos comuns, podemos citar:

- J.evar o profissional a compreender e identificar os diferentes aspectos envolvidos no processo saúde-doenÇal;

- Ampliar o repertório de recursos dos profissionais para lidar com os diferentes fatores que envolvem situaçōes de adoecimento;

- Favorecer a percepção do sofrimento e a identificação dos recursos do paciente para lidar com a doença, estimulando-o a participar do tratamento;

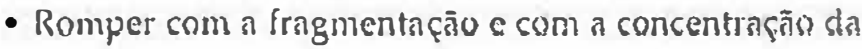
informação subre o paciente;

- Favorecer a integração teoria e prática, buscando transformar a conduta dos profissionais envolvidos;

- Possibilitar aos profissionais envolvidos entender a atu. ação clínica e terapêutica de seu colega, ampliando a consciência para os seus limites e possibilidades;

- Capacitar para interagir com o outro e para o trabalho em equipe, incentivando práticas que aliem qualidade de atenção, resolutividade das açōes e que proporcionem a educação permanente entre os profissionais;

- Promover uma prática integradora, visando à interdisciplimaridade, instituindo o cuidado como cixo estruturante na prálica em saúde;

- Possibilitar o suporte mútuo entre profissionais frente a uma prática complexa e repleta de dúvidas c ansicdade, para que possam exercê-la de forma resolutiva a eficaz.

Com relação aus objetivos específicos da Consulta Conjunta no que se refere aos profissionais envolvidos, médicose psicólogos, podemos destacar:

No que di», respeito aos medicos: 
- Ampliar a compreensāo do processo saúde-doença para além do modelo biologicista em prol de uma medicina mais humana, que leve em conta a unidade somatopsiquica do paciente;

- Capacitar o médico a dar suporte psicológico a seus pacientes c a reconhecer o seu limite de atuaçāo, favorecendo um encaminhamento adequado ao especialista em saúde mental, quando necessário;

- Comprcender a importância da psicoterapia da prática médica, assim como o seu papel terapêutico junto ao paciente;

- Instrumentalizar o médico para ver para além do sintoma.

No que se referc aos psicólogos:

- Promover a compreensāo da interaçāo corpo/mente num contexto biopsicossocial;

- Favorecer uma abordagem psicoterápica ágil, focal e criativa, adcquada ao tempo $c$ ao setting onde a consulta se desenrola;

- Levar o psicólogo a atuar na Consulta Conjunta como facilitador da comunicação, por meio da compreensāo da dinâmica da rclação médico-paciente;

- Auxiliar no diagnóstico e na prescrição de condutas terapêuticas adequadas ao estilo de vida do paciente.

Trabalhos conjuntos, entretanto, nào têm sido uma prática comum, em virtude da estruturação disciplinar compartimentalizada no que diz respeito aus conteúdos e da valorizaçāo de açōes predominantemente individuais durante a formação na área da saúde. Neste sentido, no exercício da Consulta Conjunta temos encontrado dificuldades de diferentes ordens, entre as quais podemos citar:

Junto ao médico:

- Desconhecimento teórico e prálico desta prática, uma ve\% que o trabalho integrado nāo é contemplado nos currículos da maioria das escolas médicas;

- Desconhecimento e/ou incompreensão do modelo de atençāo biopsicossocial, posto que o modelo de atençāo à saúde tem sido calcado, predominantementc, na compreensāo biologicista;

- Dificuldade de compartilhar com um profissional de outra especialidade, pela hegemonia do saber médico nos scrviços de saúde;

- Desconhecimento da funçào do psicólogo, porque a prática deste profissional é recente nas unidades de atenção geral à saúde;

- Excesso de demanda de trabalho por questōes que vão desde o ordenamento da porta de entrada do sistema de saúde ou até mesmo pelo paradigma predominantemente curativo que tem norteado as açỏes em saúde.

Junto ao psicólogo:

- Desconhecimento desta prática, embora tcoricancente tenha ciência a respeito, pois são poucas as unidades de saúde que utilizam esta metodologia de ensino em serviço;

- Equivoco de compreensão que facilita a identificação com o paciente e propicia uma aliança "contra" o médi$\mathrm{CO}$

- Desconhecimento da biomedicina ou dos mecanismos biológicos das doenças que direcionam a compreensão do processo sauide-doença, com excessiva ênfase na subjetividade em detrimento das demais dimensōes que compōem o homem;

- Exclusão ou pouca valorização dos determinantes sociais na etiologia das doenças;

- Excesso de interpretação subjetiva de dados de realidade, fatos concretos.

Para viabilizar a prática da Consulta Conjunta, têm-se utilizado algumas estratégias para identificar e diluir pontos de resistência, fomentar parcerias $\mathrm{e}$ integrar os profissionais: discussāo multidisciplinar de casos clínicos; aproximaçāo por temas afins nas discussỏes, seminários e oficinas; cncaminhamentos em que a devolução ou resposta do parecer ou da conduta traçada se faz de forma presencial; incentivo à produção conjunta para participaçāo cm eventos, artigos e pesquisas.

A atuação compartilhada sc desdobra em produção conjunta sob diferentes formatos: novas consultas em parceria para clarificaçāo diagnóstica; assunção do atendimento por um dos profissionais envolvidos, após discussāo do caso sem a presença do paciente; encaminhamentos mais precisos para especialidades e/ou locais que desenvolvam terapêuticas requeridas pela situaçāo em questāo; trabalhos de grupo com pacientes sob a coordenaçāo conjunta dos profissionsiis.

Todo o processo é construido com e para o paciente, promovendo a aproximaçāo e o diálogo, valorizando a parceria e fortalecendo a autonomia na busca do cuidado.

\section{PARA CONCLUIR}

Este é um recurso metodológico que temos utilizado para quebrar barreiras das dificuldades do trabalho conjunto, promover a compreensāo integral do processo saúde-doença c facilitar a interlocuçāo entre profissionais, visando produzir novas configuraçōes de saberes que favoreçam uma aborda. gem resolutiva das reais necessidades de saúde da população. 
A prática da Consulta Conjunta potencializa o cuidado c os momentos dos profissionais ao propiciar que, solidariamente, partilhem problemas, reflitam sobre eles e busquem soluçōes, evitando a prática impessoal e a reprodução padronizada. Este tipo de atuaçāo torna o cuidado mais extenso e mais intenso, e possibilita a construção de movimentos conjuntos, viabilizando a mudança dos profissionais e das práticas de satide.

\section{REFERÊNCIAS}

1. Feuerwerker LCM. Estratëgias para a mudança da formaçāo dos profissionais de satide. Cademo CE 2002; 2(4): 11-24.

2. Ribeiro ECO. Educaçāo Permanente em Saúde. In: Marins JjN, Rego S, Lampert JB, Arauijo JCC (Orgs.). Educação Médica em transformação: instrumentos para a cosıstrução de novas realidades. São Paulo. Hucitec/ABEM; 2004.
3. Ferrari $H$, Luchina $I$, Luchina $N$. La interconsulta medicopsicologica en el marco hospitalario. Buenos Aires: Nueva Vision; 1980.

4. Mello FJ. Isaac Luchina e a interconsulta médico-psicológica In:Rodrigues Branco, RFG. A relaçảo com o paciente. Rio de Janeiro: Guanabara Koogan; 2003.

\section{Endereço para correspondência}

Júlio de Mello Filho e-mail: pape@uerj.br

\section{Lia Márcia Cruz da Silveira}

Rua Voluntários da Pátria, 190/323 - Botafogo 22070-010 - Rio de Janeiro - RJ e-mail: lia.silveira@uol.com.br 